\title{
LA EXTINCIÓN DE LA RELACIÓN FUNCIONARIAL Y LA REHABILITACIÓN DE LA CONDICIÓN DE FUNCIONARIO PÚBLICO EN LA JURISPRUDENCIA DEL TRIBUNAL SUPREMO ENTRE LOS ANOS 2009 Y 2015
}

\author{
Maria AlborCh GisBerT \\ Consultora de Recursos Humanos \\ mariag1992@gmail.com
}

\section{INTRODUCCIÓN}

A lo largo de la exposición nos vamos a centrar en analizar la jurisprudencia del Tribunal Supremo entre los años 2009 y 2015 acerca de la pérdida de la condición de funcionario y su rehabilitación, en la cual observaremos que sólo llegan a su Sala de lo Contencioso-Administrativos conflictos relativos a la pérdida de la condición de funcionario por la condena a una pena de inhabilitación (principal o accesoria) o por la imposición de una sanción administrativa que determina la extinción de la relación funcionarial, que en ocasiones podrá concurrir con una condena penal.

\section{ESPECIAL ATENCIÓN A LA PÉRDIDA DE LA CONDICIÓN DE FUNCIONARIO COMO CONSECUENCIA DE CONDENA A PENA DE INHABILITACIÓN POR LA COMISIÓN DE UN DELITO. CLASIFICACIÓN SEGÚN LA NATURALEZA DEL DELITO}

\section{Delito de infidelidad en la custodia de documentos}

Dentro de la casuística de la jurisprudencia del TS sobre este tipo de delitos vamos a analizar la Sentencia de 26 de junio de $2013^{1}$ dictada por la Sala de lo Contencioso-Administrativo. Doña Belén formaba parte del

${ }^{1}$ Vid. STS, Sala de lo Contencioso-Administrativo, Sección 7. a , de 26 de junio de 2013 (RJ/2013/6016, recurso núm. 201/2012, ponente: Excmo Sr. Nicolás Maurandi Guillén). 
Cuerpo Auxiliar de la Administración de la Seguridad Social y cometió un delito de infidelidad en la custodia de documentos contemplado en el art. 413 CP. Fue condenada por la Audiencia Provincial de Barcelona a pena de prisión, multa e inhabilitación para el derecho de sufragio pasivo, así como a una pena de inhabilitación especial para empleo o cargo público por un tiempo de tres años. A la hora de determinar su condena se tuvo en cuenta la circunstancia analógica de alteración psíquica.

La condena está motivada en el hecho de que la autora cogió tres expedientes del Ministerio de Trabajo y los guardó en su coche sin que hubiera motivo para que los tuviera en su posesión fuera del mismo. Posteriormente dichos documentos fueron hallados en su vehículo por los Mossos d'Esquadra.

En base a la firmeza de la sentencia de la Audiencia Provincial que condenaba a la autora a la pena de inhabilitación y en virtud de la resolución de la Subsecretaría de Trabajo y Asuntos Sociales, Belén perdió su condición de funcionaria tal y como se establece en los arts. 63.e) y 66 EBEP.

$\mathrm{Al}$ cabo de los años solicitó su rehabilitación en la condición de funcionario, la cual fue desestimada por Acuerdo del Consejo de Ministros. Por tanto, ante dicho resolución interpuso recurso contencioso-administrativo cuya pretensión principal era la anulación de dicho acuerdo y el reconocimiento de su derecho a ser rehabilitada como funcionaria. Frente a la propuesta de resolución que denegaba su rehabilitación, la demandante alegó que el informe emitido por el último centro donde estuvo destinada deja abierta la posibilidad de su incorporación en otras dependencias; que la conducta por la que fue condenada era una conducta aislada; que el daño y perjuicio causado fue aminorado por el tribunal mediante la atenuante aplicada; que ha transcurrido un gran lapso de tiempo, y, por tanto, debe ser tenido en cuenta; que no cuenta con antecedentes desfavorables, señalando finalmente que la sanción que se le impuso fue anulada. En los fundamentos de Derecho señala que los criterios orientadores del art. 6 del RD 2669/1998 «deben conducir a concederle el derecho a la rehabilitación».

Dicho artículo contiene los criterios para la formulación de la propuesta de resolución y se debe tener en cuenta que se trata de criterios orientadores. La Sala señala que no se debe olvidar que «la idea o finalidad presente en la rehabilitación es determinar si la incapacidad para ser funcionario, que en principio lleva consigo la condena penal de inhabilitación, resulta excesiva en algunos casos cuando el delito es ajeno al cargo funcionarial que se desempeñaba, no ha habido perjuicio para el servicio público 
y tampoco los hechos han tenido gravedad», y, además, que la Administración deberá tomar su decisión en base a los criterios señalados.

La Sala determina que no cabe la anulación de la resolución, ya que la misma se encuentra suficientemente motivada y no revela una actuación que pueda ser tachada de errónea o arbitraria. Para tomar dicha decisión se ha tenido en cuenta que el delito por el que se condenada a la autora contempla una conducta tipificada para funcionarios públicos; que el Consejo de Ministros emite una resolución motivada basada en la relación entre el hecho delictivo y el desempeño funcionarial, la gravedad de los hechos y el informe emitido por el subsecretario de trabajo; que se pone de manifiesto la proximidad entre el hecho y la condición de la autora, así como la gravedad de los hechos por el incumplimiento de los deberes básicos y la repercusión negativa para el correcto funcionamiento de la Administración. Por tanto, la condena penal no puede considerarse excesiva y la denegación de rehabilitación no es contraria a la reinserción social. Por todo ello, el TS desestima el recurso contencioso-administrativo interpuesto por Belén frente al Acuerdo del Consejo de Ministros denegatorio de la rehabilitación en su condición de funcionario.

\section{Delito de descubrimiento y revelación de secretos}

Dentro del ámbito de los delitos de descubrimiento y revelación de secretos del capítulo I del título X del Código Penal, nos encontramos ante la Sentencia del TS de 29 de marzo de $2010^{2}$ donde se resuelve el recurso contencioso-administrativo interpuesto por la representación del guardia civil Julio contra el Acuerdo de Consejo de Ministros denegatorio de la rehabilitación en su condición de funcionario, cuya pérdida fue consecuencia de su condena a la pena de inhabilitación especial para empleo y cargo público por la Sentencia de 12 de mayo de 2003 que le declaró autor de dicho delito por haber comunicado al gerente y empleado del hotel Argar de Vera (establecimiento dedicado al alterne) la proximidad de la realización de una inspección. Julio sostiene que debería haber sido rehabilitado en su condición de funcionario público debido a que ha operado el silencio administrativo positivo al haber transcurrido más de tres meses

2 Vid. STS, Sala de lo Contencioso-Administrativo, Sección 7.a , de 29 de marzo de 2010 (RJ/2010/5602, recurso núm. 546/2008, ponente: Excmo. Sr. Pablo Lucas Murillo de la Cueva). 
desde la solicitud, plazo contemplado por el art. 43.2 LRJAP-PAC. Además, como pretensión subsidiaria sostiene que el acuerdo recurrido infringe el art. 88.1 de la Ley de Régimen Personal del Cuerpo de la Guardia Civil $^{3}$, porque no se tuvieron en cuenta las circunstancias ni la entidad del delito cometido y, además, en la sentencia recurrida demostró que cometió una «indiscreción» por lo que se le impuso la pena mínima. El abogado del Estado niega que nos encontremos ante un caso de silencio positivo y señala que la decisión del Consejo de Ministros fue ajustada a Derecho, ya que actuó atendiendo a las circunstancias del delito cometido por tratarse de un abuso de la condición de guardia civil y estar ampliamente relacionado con el servicio. Además recuerda que la concesión de la rehabilitación no es automática, sino que exige una valoración de las circunstancias y de la entidad del delito, ante lo cual el Consejo de Ministros tiene un amplio margen de discrecionalidad. La Sala entiende que el recurso debe ser estimado porque de ningún lugar se desprende que el silencio deba ser considerado negativo, aunque no se debe tener en cuenta el plazo de tres meses alegado por el recurrente, sino el de seis meses contemplado en el art. 42.2 LRJAP-PAC, del cual dispone la Administración para dictar una resolución expresa. Por todo ello, Julio debe ser rehabilitado en su condición de funcionario público.

\section{Delitos cometidos por funcionarios de prisiones: tráfico de drogas, torturas y lesiones}

Otro de los variados ejemplos encontrados en la casuística de la jurisprudencia del TS son los delitos cometidos por funcionarios de prisiones. Se procederá a analizar la Sentencia del TS de 14 de septiembre de $2015^{4}$ que resuelve el recurso contencioso-administrativo interpuesto por la representación de Marcos, funcionario del Cuerpo de Ayudantes de Instituciones Penitenciarias, contra el Acuerdo de Consejo de Ministros denegatorio de la rehabilitación en su condición de funcionario, cuya pérdida fue consecuencia de su condena a la pena de prisión, multa e inhabilitación especial para el ejercicio de empleos, cargos públicos, profesión u oficio durante el

${ }^{3}$ Ley 42/1999, de 25 de noviembre, de Régimen del Personal del Cuerpo de la Guardia Civil (vigente hasta el 30 de noviembre de 2014, BOE-A-2014-12408).

${ }^{4}$ Vid. STS, Sala de lo Contencioso-Administrativo, Sección 7.', de 14 septiembre de 2015 (RJ/2015/230449, recurso núm. 914/2014, ponente: Excmo.: Sr. Pablo de Lucas Murillo de la Cueva). 
tiempo de duración de la primera por la Sentencia de 11 de noviembre de 2003 que le declaró autor del delito de tráfico ilícito de drogas que causan grave daño a la salud pública (art. $368 \mathrm{CP}$ ) por haberse dedicado a la venta de cocaína fuera del establecimiento público donde prestaba sus servicios.

Cabe señalar que, además de la condena penal, se abrió expediente disciplinario que dio lugar a la imposición de la sanción de tres años de suspensión, la cual nunca fue cumplida debido a la pérdida de la condición de funcionario.

Una vez cumplidas las penas, Marcos solicitó la rehabilitación en dos ocasiones, siendo denegada ambas veces. En su solicitud señaló que ya se habían extinguido todas las responsabilidades derivadas del delito (habían transcurrido once años), que carecía de antecedentes penales y que había tenido una conducta intachable posteriormente. También indicó que no causó perjuicio al servicio público y que el hecho delictivo se produjo al margen de su actuación como funcionario y fuera de establecimiento penitenciario. Alegó que disponía de un informe favorable a su rehabilitación y que la pena de inhabilitación no fue solicitada por el Ministerio Fiscal, infringiéndose el principio acusatorio. Finalmente señaló que en la sentencia no se indicaba el empleo sobre el que debía recaer la inhabilitación, debiendo declararse nula de pleno Derecho e iniciarse un proceso de revisión de oficio, recalcando además que la pena accesoria sólo podía durar el tiempo de la condena.

El Consejo de Ministros denegó la rehabilitación siguiendo los criterios orientativos del RD 2669/1998 y alegó que su decisión se había apoyado en el informe negativo de la Secretaría General de Instituciones Penitenciarias, atendiendo a la gravedad de su conducta, a su actuación dolosa y al perjuicio que ocasionó al servicio. Recalcó que el transcurso del tiempo no mitiga la gravedad de los hechos y que los antecedentes penales por sí solos no son motivos para conceder la rehabilitación. En lo referente a la falta de indicación del empleo afectado, la Sala alega literalmente que:

«Recuerda la jurisprudencia para la que la declaración administrativa de la pérdida de la condición de funcionario de los condenados no es sanción ni ejecución de sentencia, sino mera aplicación del régimen funcionarial ante la pérdida de la aptitud que implica la condena a modo de condición resolutoria ope legis».

La Sala recuerda la excepcionalidad de la concesión de la rehabilitación en la condición de funcionario y que el cumplimiento de la condena 
es el presupuesto para solicitar la misma o para iniciar de nuevo los cauces para acceder a la función pública. Como en otras sentencias que hemos estudiado, la Sala señala que la finalidad de la rehabilitación es determinar si la pena impuesta es excesiva en algunos casos en los que el delito es ajeno a la condición funcionarial y no habido perjuicio para el servicio ni los hechos han revestido excesiva gravedad.

El recurso debe ser desestimado porque el Acuerdo se encuentra lo suficientemente motivado y no es arbitrario. Es muy importante recalcar que «quienes solicitan la rehabilitación no tienen derecho a obtenerla, sino a que su solicitud se decida conforme al procedimiento previsto» y en base a los criterios orientadores recogidos en el art. 6.2 del RD 2669/1998.

\section{Delitos cometidos por la Policía Nacional: homicidio, detención ilegal, falsedad documental, lesiones y delitos contra la salud pública}

En el ámbito de los delitos cometidos por integrantes de las Fuerzas y Cuerpos de Seguridad del Estado se va a analizar la Sentencia del TS de 18 de diciembre de $2014^{5}$ en la que la Sala de lo Contencioso-Administrativo del TS resuelve el recurso interpuesto por Andrés frente al Acuerdo del Consejo de Ministros que deniega su rehabilitación de la condición de funcionario.

Andrés pertenecía al Cuerpo Nacional de Policía y fue condenado a una pena de inhabilitación especial, entre otras, por la comisión de un delito de homicidio imprudente cuando se encontraba desempeñando sus funciones. Ante un aviso de robo, el autor acudió al lugar de los hechos y al inspeccionar la zona se percató de que había un vehículo detenido en un semáforo ocupado por dos sujetos. Se acercó al mismo y reconoció a uno de los ocupantes, ya que ya había sido detenido en alguna ocasión, por lo que procedió a dar el alto al vehículo y, ante la evasiva de los ocupantes, efectuó dos disparos con su arma reglamentaria, alcanzando con uno de ellos al conductor del vehículo, el cual perdió la vida horas más tarde.

El autor del delito interpuso recurso de casación, el cual fue desestimado por el TS. En base a la condena penal, el secretario de Estado de Seguridad dictó resolución que determinaba la pérdida de su condición de

5 Vid. STS, Sala de lo Contencioso-Administrativo, Sección 7.', de 18 de diciembre de 2014 (RJ/2014/251, recurso núm. 558/2012, ponente: Excmo. Sr. Nicolás Maurandi Guillén). 
funcionario, que años más tarde intentó recuperar solicitando la rehabilitación, la cual fue denegada por el Consejo de Ministros.

La Sala considera que se debe tener en cuenta que la sentencia penal justifica la imposición de la pena en el hecho de que, en base a las pruebas practicadas, se demostró que los medios empleados excedían ampliamente de la finalidad de detener el vehículo y además se le exigía al autor una mayor cautela en su actuación debido al cargo que ocupaba. La acción de disparar no era proporcional, y menos cuando Andrés ya había reconocido a uno de los integrantes del vehículo, persiguiéndosele en este caso por un delito de menor gravedad que no suponía riesgos ni para él ni para terceros. El autor no se comportó con la cautela, congruencia y necesidad que la situación exigía, y además infringió de forma voluntaria una norma de cuidado impuesta por la Ley de Fuerzas y Cuerpos de Seguridad del Esta$\mathrm{do}^{6}$ en lo referente al uso de armas de fuego.

El autor alega ante el TS que concurren de manera favorables lo criterios del art. 6.2 del RD 2669/1998, debido a su falta de antecedentes penales, su buena conducta profesional antes y después de la comisión del delito, la imposición de la pena es su grado mínimo y el largo tiempo transcurrido desde la comisión de los hechos. Además señala que en los informes emitidos se le señala como un funcionario modélico.

La Sala recuerda la finalidad de la rehabilitación y señala que la Administración no goza de libertad para decidir de forma arbitraria sobre ella, sino que debe atenerse a los criterios señalados por el RD 2669/1998. Considera que la denegación de la rehabilitación no debe ser anulada, ya que es claramente motivada en base a los hechos. Hace referencia a los elementos destacados por el Acuerdo del Consejo de Ministros para denegar la rehabilitación, señalando que se atendió al daño y servicio causado al servicio público, a la conexión de los hechos delictivos con el cargo funcionarial y a la gravedad de los hechos. Por tanto, los criterios orientadores han sido aplicados correctamente ya que el comportamiento de Andrés denota una muy reprochable desidia profesional, debido a que éste no reparó en el hecho de que las armas de fuego deben ser usadas de forma excepcional cuando su utilización devenga necesaria.

Por todo ello, la Sala desestima el recurso contencioso-administrativo interpuesto contra el Acuerdo del Consejo de Ministros que denegó la rehabilitación en la condición de funcionario a Andrés.

${ }^{6}$ Ley Orgánica 2/1986, de 13 marzo, de Fuerzas y Cuerpos de Seguridad (en adelante LOFCS). 


\section{Delito de falsedad en documento público}

La comisión de un delito de falsedad en documento público también puede dar lugar a la pérdida de la condición de funcionario. La Sentencia del TS de 14 de octubre de $2010^{7}$ nos relata el caso de Avelino, integrante del Cuerpo de Auxiliares Postales y de Telecomunicación, que fue condenado por la Audiencia Provincial de Valencia mediante la Sentencia de 18 de diciembre de 2003 a pena de prisión e inhabilitación especial para el desempeño de su profesión al ser considerado autor de un delito de falsedad en documento oficial en concurso ideal con un delito de apropiación indebida. Avelino, aprovechando su condición de funcionario público, con ánimo de obtener beneficios a costa de los usuarios de correos, se fue apropiando de cantidades relativas a los giros postales dirigidos a Gumersindo, en cuyos documentos estampaba una firma simulando la del destinatario, reuniendo una cifra aproximada de 11.000 euros.

Una vez firme la sentencia penal, la directora de recursos humanos de la Sociedad Estatal de Correos y Telégrafos, S. A., declaró la pérdida de su condición de funcionario. Al cabo de tres años y una vez extinguidas todas sus responsabilidades penales, Avelino solicita la rehabilitación de la condición de funcionario, la cual fue denegada por el Consejo de Ministros tomando como referencia el informe desfavorable emitido por el subdirector general de gestión de personal de Correos, en el que constaba que la conducta por la que había sido condenado afectaba a la esencia de su condición de funcionario y que con ésta había lesionado la especial confianza depositada por los usuarios de este servicio público.

Es por ello que Avelino interpone recurso contencioso-administrativo ante el TS solicitando a la Sala su estimación, con la consecuente anulación del Acuerdo del Consejo de Ministros que declaraba la pérdida de su condición de funcionario. El actor plantea que fue excesiva la decisión de privarle de su condición de funcionario y que es conveniente que se le conceda la rehabilitación, ya que se estaría elevando la gravedad de la situación de forma antijurídica por no tenerse en cuentas las circunstancias favorables y por haber cumplido su pena.

Ante ello, la Sala señala que según el EBEP la rehabilitación tiene carácter excepcional y que los órganos de gobierno de las Comunidades

7 Vid. STS, Sala de lo Contencioso-Administrativo, Sección 7. ade 14 de octubre de 2010 (RJ/2010/7257, recurso núm. 117/2009, ponente: Excmo. Sr. Juan José González Rivas). 
Autónomas deberán tomar tal decisión en base a las circunstancias y entidad del delito, debiendo ser conforme a Derecho. También señala que la Administración no goza de libertad para decidir sobre el tema, sino que deberá ajustarse a los criterios establecidos por el RD 2669/1998. En ningún caso se debe olvidar que la finalidad de la rehabilitación es

«determinar si la incapacidad para ser funcionario que, en principio, lleva consigo la pena de inhabilitación, resulta excesiva en algunos casos, cuando el delito es ajeno al cargo funcionarial que se desempeñaba, no ha habido perjuicio para el servicio público y tampoco los hechos han tenido gravedad».

Haciendo un examen de los hechos, la Sala valora que en el informe negativo del subsecretario de gestión de personal se reflejaba que la conducta del autor estaba directamente relacionada con su condición de funcionario causando un grave perjuicio al servicio público que desempeñaba, ya que se lesionó la especial confianza que los usuarios esperan recibir. También señala que la presencia del recurrente puede comprometer gravemente la eficacia y calidad de los servicios.

Los hechos enjuiciados fueron sancionados como un único delito, aunque se cometieron continuadamente, denotándose la gravedad de la conducta al no tratarse de un hecho aislado y justificable. Aunque el autor reparase los daños cometidos, su actuación perjudica a la imagen de Correos y Telégrafos, y no se elimina en ningún momento la especial gravedad de los hechos.

Aunque se puedan tener en consideración otros factores introducidos por el RD 2669/1998, principalmente se debe atender a «las circunstancias y entidad del delito cometido», y en este caso los hechos fueron de tal magnitud «que el actor mereció el máximo reproche del ordenamiento que implica incidir en una conducta tipificada en el Código Penal».

Por tanto, la denegación de la rehabilitación viene condicionada por la comisión de los hechos delictivos y por el cuerpo de doctrina consolidada al respecto. La Sala considera que resulta suficientemente justificado que Avelino no sea rehabilitado en su condición de funcionario en base a la argumentación del Consejo de Ministros en el Acuerdo denegatorio, ya que se trata de una decisión razonada y razonable. Los hechos, las circunstancias y la fundamentación jurídicas se adecuan entre sí y, por tanto, se debe confirmar la pérdida de la condición de funcionario del recurrente. 
Por todo ello, la Sala de lo Contencioso-Administrativo desestima el recurso contencioso-administrativo interpuesto por Avelino ante el Acuerdo del Consejo de Ministros que deniega la rehabilitación en su condición de funcionario público.

\section{Delito de malversación}

En lo referente al delito de malversación recogido en nuestro Código Penal se va a analizar la Sentencia del TS de 18 de diciembre de $2012^{8}$, donde se resuelve el recurso contencioso-administrativo planteado por Jacobo frente a la resolución que deniega su rehabilitación como funcionario público. Jacobo perdió su condición de funcionario público debido a que, entre 1998 y 1990, se apropió en varias ocasiones, y con propósito de hacerlas suyas, de diferentes cantidades de dinero que recibió de contribuyentes de la Seguridad Social, sin ingresarlas en la Tesorería General de la Seguridad Social. Por ello fue condenado a una pena de inhabilitación absoluta por la comisión de un delito continuado de malversación de caudales públicos, además de la condena de prisión a la que iba aparejada. Tras el cumplimiento de la pena solicitó su rehabilitación, que le fue denegada mediante el Acuerdo del Consejo de Ministros de 1 de abril de 2011. Es por ello que presentó recurso contencioso-administrativo ante el TS alegando que el acuerdo debía ser anulado y de esa forma ser rehabilitado en su condición de funcionario, ya que durante sus treinta años como funcionario nunca ocasionó problemas; que la comisión del delito se debió a una situación personal grave de la que derivaron necesidades económicas, lo que dio lugar a dicha actuación puntual; que obtuvo indulto parcial de su condena penal y ya han transcurrido más de veintidós años desde que fue condenado, y desde entonces no había cometido ninguna conducta reprochable y se habían saldado sus responsabilidades. Además, el actor alegó que se habían aplicado de forma incorrecta los principios del art. 6.2 del RD 2669/1998, que no se habían aportado informes referentes a su conducta profesional durante sus treinta años de servicio y, además, factores como el daño al servicio, la relación con el hecho delictivo, la gravedad de los hechos y la duración de la condena habían sido ponderados conjun-

${ }^{8}$ Vid. STS, Sala de lo Contencioso-Administrativo, Sección 7.a, de 18 de diciembre de 2012 (RJ/2013/1051, recurso núm. 332/2011, ponente: Excmo. Sr. Nicolás Maurandi Guillén). 
tamente sin más prueba que la del proceso penal. Ante tales alegaciones, la Sala recuerda que la finalidad de la rehabilitación es

«determinar si la incapacidad para ser funcionario, que en principio lleva consigo la condena penal de inhabilitación, resulta excesiva en algunos casos cuando el delito es ajeno al cargo funcionarial que se desempeñaba, no ha habido perjuicio para servicio público y tampoco los hechos han tenido gravedad».

Además, la Administración no goza de libertad para rehabilitar, sino que ha de decidir según los criterios del RD 2669/1998. Por todo ello, el Acuerdo que deniega la rehabilitación no debe ser anulado, ya que se encuentra claramente motivado y es coherente con su finalidad, no revelando una ponderación que pueda considerarse errónea o arbitraria por excesiva. La Sala cree conveniente aclarar que los hecho delictivos se encontraban directamente relacionados con el cargo público del recurrente; que no se trató de un hecho puntual, debido a que se produjo de forma continuada; que la especial publicidad del delito ha causado grave daño al servicio público y tiene especial trascendencia para la imagen del mismo. El periodo de tiempo transcurrido desde la condena no afecta a la gravedad de la misma y, además, los antecedentes no son el único y determinante factor a valorar. El informe de la Subsecretaría de Trabajo e Inmigración es desfavorable y el Acuerdo denegatorio no puede ser considerado falto de motivación, ya que expresa claramente las razones que dan lugar a dicho resultado. Por todo ello, no puede considerarse excesiva la pérdida de la condición de funcionario en base a la condena penal y ésta no es contradictoria con el indulto parcial, ya que este último pretende facilitar la reinserción social, y la rehabilitación lo que pondera es «la no concurrencia en el demandante del superior nivel de irreprochabilidad que requiere la permanencia en un cuerpo de funcionarios de la Administración Pública». Por todo lo expuesto, la Sala desestima el recurso contencioso-administrativo interpuesto por Jacobo ante el Acuerdo del Consejo de Ministros que deniega la rehabilitación de la condición de funcionario.

\section{Delito de cohecho}

Finalmente se va a estudiar el delito de cohecho, que en el caso que nos ocupa fue cometido por Melchor, perteneciente al Cuerpo General Auxiliar 
de la Administración del Estado, cuyo último destino fue la Jefatura Provincial de Tráfico. En la Sentencia del TS de 21 de enero de $2015^{9}$ se relata que en el año 2002, a sabiendas de los problemas de visión de Victorino, Melchor le propuso, a cambio del pago de 3.000 euros, facilitarle la obtención del permiso de conducción, simulando para ello el canje de su permiso de conducción holandés inexistente y elaborando a partir de él el permiso de conducción. Además, modificó las anotaciones negativas acerca de Victorino que figuraban en los ficheros, dando apariencia de que éste las había superado, sin aportar prueba documental que lo justificara.

Ante la concurrencia de dichos hechos, Melchor fue condenado como el autor de un delito de cohecho y falsedad documental a pena de prisión e inhabilitación especial para empleo público por cada uno de los delitos cometidos. Una vez la sentencia adquirió firmeza, Melchor perdió su condición de funcionario en virtud de la resolución de 29 de mayo de 2008 dictada por el Ministerio del Interior.

En el año 2014 solicitó su rehabilitación, la cual fue denegada por el Acuerdo de 28 de enero del Consejo de Ministros, y es por ello que se interpuso recurso contencioso-administrativo ante el TS. Melchor alega que se ha infringido el art. $42 \mathrm{CP}$, ya que en la sentencia penal no figuran los empleos, cargos u honores afectados por la doble inhabilitación especial con duraciones diferentes según el delito. Además alega contradicciones en el fallo perjudiciales para su persona, señalando que la inhabilitación especial a la que fue condenado tiene el alcance de una inhabilitación absoluta. Señala que estos tipos de inhabilitación deben diferenciarse y tenerse en cuenta para estimar su solicitud de rehabilitación, ya que si durante el cumplimiento de su pena de inhabilitación pudo ejercer puestos análogos dentro de la función pública, también debería habérsele concedido la rehabilitación.

La Sala destaca que el TS no puede revisar la corrección jurídica de la sentencia penal, sino que su labor es valorar si la misma fue debidamente interpretada y aplicada por la Administración en el Acuerdo denegatorio dictado por el Consejo de Ministros. También se puntualiza que quedaba claro que la inhabilitación especial afectaba al cuerpo funcionarial al que pertenecía el recurrente, y que la sentencia penal impuso dos penas de inhabilitación de duración diferente, cada una de ellas relativa a los delitos cometidos. Finalmente señala que la pérdida funcionarial no fue a conse-

9 Vid. STS, Sala de lo Contencioso-Administrativo, Sección 7. a , de 21 de enero de 2015 (RJ/2015/223, recurso núm. 509/2013, ponente: Excmo. Sr. Nicolás Maurandi Guillén). 
cuencia de la aplicación indebida de una pena de inhabilitación absoluta, sino en virtud de la condena a la pena de inhabilitación especial que supone la privación definitiva de empleo o cargo sobre la que recaiga. Es por todo ello que la Sala decide desestimar el recurso contencioso-administrativo interpuesto por Melchor contra el Acuerdo del Consejo de Ministros que le deniega la rehabilitación de su condición de funcionario público.

\section{CONCLUSIONES}

En base a la normativa estudiada y a los pronunciamientos del Tribunal Supremo en lo referente a la pérdida de la condición de funcionario público y a la posibilidad de rehabilitación de la misma, he llegado a la conclusión de que existe cierta confusión entre los afectados ante la figura de la rehabilitación, ya que se confunde el derecho a solicitar la rehabilitación con el derecho a obtenerla. La Sala de lo Contencioso-Administrativo del Tribunal Supremo ha señalado en varias ocasiones que la solicitud de rehabilitación da derecho a que se decida conforme al procedimiento previsto para ello en el RD 2669/1998 y atendiéndose a los criterios de su art. 6.2, y que en ningún momento existe un derecho automático para su concesión por el hecho de que se hayan extinguido las responsabilidades.

Para resolver estos conflictos se encuentra el Tribunal Supremo, que nos ha demostrado en sus múltiples pronunciamientos que existen unas bases asentadas a la hora de dar respuesta a las solicitudes de aquellos funcionarios apartados del servicio e interesados en recuperar su condición que consideren que la condena que les fue impuesta resulta excesiva en relación con la entidad del delito cometido. 
